\title{
PENINGKATAN KOMPETENSI GURU DALAM MENYUSUN RPP YANG DISEDERHANAKAN MELALUI SUPERVISI AKADEMIK BERKELANJUTAN
}

\author{
Jasmin \\ SMA Negeri 1 Bunyu, Kalimantan Utara, Indonesia \\ Email: jasminpasaka12@gmail.com
}

\begin{abstract}
Abstrak
Pendidikan adalah usaha sadar dan terencana untuk mewujudkan suasana belajar dan proses pembelajaran agar peserta didik secara aktif mengembangkan potensi dirinya untuk memiliki kekuatan spiritual keagamaan, pengendalian diri, kepribadian, kecerdasan, akhlak mulia, serta keterampilan yang diperlukan dirinya dan masyarakat. Penelitian bertujuan untuk mendeskripsikan: 1) Peningkatan kemampuan guru SMA Negeri 1 Bunyu dalam menyusum perangkat Pembelajaran, 2) peningkatan kemampuan guru di SMA Negeri 1 Bunyu dalam menyusun RPP yang disederhanakan atau yang sering disebut RPP satu lembar. (3.) Membuat program semester. (4.) Membuat rencana pelaksanaan pembelajaran (5.) dan membuat program ulangan/evaluasi. Dari kelima dokumen tersebut di atas, RPP merupakan persiapan paling minimal untuk seorang guru ketika hendak mengajar. Penelitian ini merupakan penelitian kualitatif, dengan pendekatan deskriptif kualitatif fenomenologik. Data kualitatif diperoleh dari lembar observasi serta wawancara. Sedangkan data kuantitatif diperoleh dari hasil tes. Tes terdiri atas dua siklus, setidaknya ada empat langkah yaitu (1) Perencanaan pertemuan, (2) Observasi, (3) Pertemuan berikutnya, (4) Refleksi kolaborasi. Manfaat dari penelitian ini diharapkan dapat meningkatkan kompetensi guru dalam melaksanakan tugas-tugasnya sehingga menjadi lebih professional, meningkatkan prestasi siswa dalam pembelajaran, dan pada akhirnya meningkatkan mutu sekolah.
\end{abstract}

Kata Kunci: Supervisi Akademik; kemampuan guru; kegiatan pembelajaran

\section{Abstract}

Education is a conscious and planned way of effort for the learning atmosphere and learning process so that active learners have the potential for the power of having religious spiritual, self-life, disquitarian, intelligence, noble morals, as well as skills that skills both self and society. Research to describe: 1) Capital of teachers of SMA Negeri 1 Bunyu in heat-eating devices, 2) prancing teachers at SMA Negeri 1 Bunyu in simplified RPP or often mentioning RPP one sheet. (3.) Create a semester program. (4.) Create a training exercise plan (5.) and create a replay/jasmine program. From the document from where above, RPP is a minimum preparation for teachers when teaching ladybugs. This research is qualitative research, with qualitative descriptive phenomenological. Qualitative data from observation sheets as well as stadiums. While quantitative data from the test results. The test consists of two worlds, there are at least four steps, namely (1) Planning Meeting, (2) Observation, (3) Next Meeting, (4) Re-collaboration. The benefits of this research could improve teachers jam teachers in themselves are

$\begin{array}{ll}\text { How to cite: } & \text { Jasmin (2021) Peningkatan Kompetensi Guru dalam Menyusun RPP yang Disederhanakan Melalui } \\ & \text { Supervisi Akademik Berkelanjutan, Syntax Idea, 3(7). https://doi.org/10.36418/syntax- } \\ & \text { idea.v3i7.1313 } \\ \text { E-ISSN: } & \text { 2684-883X } \\ \text { Published by: } & \text { Ridwan Institute }\end{array}$


subjected to tasks so that it becomes more professional, student achievement in 11 2019, and at that time the peak improves the quality of the school.

Keywords: academic supervision; teacher ability;learning activities

\section{Pendahuluan}

Pendidikan adalah usaha sadar dan terencana untuk mewujudkan suasana belajar dan proses pembelajaran agar peserta didik secara aktif mengembangkan potensi dirinya untuk memiliki kekuatan spiritual keagamaan, pengendalian diri, kepribadian, kecerdasan, akhlak mulia, serta keterampilan yang diperlukan dirinya dan masyarakat. Pendidikan meliputi pengajaran keahlian khusus, dan juga sesuatu yang tidak dapat dilihat tetapi lebih mendalam yaitu pemberian pengetahuan, pertimbangan dan kebijaksanaan. Salah satu dasar utama pendidikan adalah untuk mengajar kebudayaan melewati generasi (Hidayat, 2012).

Teknologi dan Informasi melaju sangat cepat di abad 21. Pendidikan dituntut untuk adaptif menyikapi perkembangan zaman. Cepatnya laju perubahan perlu diimbangi dengan praktik pendidikan yang sesuai dengan tuntutan zaman (Akhwani, 2020). Pendidikan merupakan unsur utama dalam meningkatkan kualitas sumber daya manusia. Kerangka pendidikan abad 21 mengalami penyesuaiandengan kompetensi yang dibutuhkan.The Partnership for 21st Century Learning telah menggagas kompetensi yang harus dikuasi siswa, 1) learning and innovative skills (Critical Thinking, Creative, Communication, Cooperation), 2) Knowledge, Media and Technology Skill and 3) life and career skills (Rini \& Muhid, 2021), Menurut (Gelen, 2018). Untuk mencapai kompetensi tersebut dibutuhkan guru professional. Guru yang tidak hanya memiliki pengetahuan tetapi juga memiliki keterampilan dansikap secara terintegras

Menurut Ki Hajar Dewantara, pendidikan adalah tuntutan di dalam hidup tumbuhnya anak-anak, adapun maksudnya, pendidikan yaitu menuntun segala kekuatan kodrat yang ada pada anak-anak itu, agar mereka sebagai manusia dan sebagai anggota masyarakat dapat mencapai keselamatan dan kebahagiaan setinggi-tingginya. Untuk mencapai tujuan tersebut tentunya dibutuhkan strategi yang disebut dengan strategi pembelajaran. Dalam strategi pembelajaran terkandung tiga hal pokok yakni perencanaan, pelaksanaan dan evaluasi (Sugiarta, Mardana, \& Adiarta, 2019).

Pendidikan karakter bertujuan untuk meningkatkan mutu proses dan hasil pendidikan yang mengarah pada pendidikan karakter dan akhlak mulia pembelajar secara utuh, terpadu, dan seimbang, sesuai dengan standar kompetensi lulusan pada setiap satuan pendidikan. Melalui pendidikan karakter pembelajar diharapkan mampu secara mandiri meningkatkan dan menggunakan pengetahuannya, mengkaji, dan menginternalisasikan, serta mempersonalisasikan nilai-nilai karakter dan akhlak mulia sehingga terwujud dalam perilaku sehari-hari (Harun, 2013). Pendidikan karakter merupakan upaya pembentukkan karakter yang dipengaruhi oleh lingkungan. Hal ini selaras dengan pernyataan (Hariyanto, 2013) yang mengungkapkan bahwa karakter sebagai nilai dasar yang membangun pribadi seseorang, terbentuk baik karena pengaruh 
Peningkatan Kompetensi Guru dalam Menyusun RPP yang Disederhanakan Melalui Supervisi Akademik Berkelanjutan

hereditas maupun pengaruh lingkungan, yang membedakan dengan orang lain, serta diwujudkan dalam sikap dan perilakunya dalam kehidupan sehari-hari.

Perencanaan program berfungsi untuk memberikan gambaran dan arah pelaksanaan pembelajaran sehingga pembelajaran menjadi terarah dan efisien. Salah satu bagian dari perencanaan pembelajaran yang sangat penting dibuat oleh guru sebagai pengarah pembelajaran adalah Rencana Pelaksanaan Pembelajaran (RPP). Rencana Pelaksanaan Pembelajaran (RPP) merupakan instrumen perencanaan yang lebih spesifik dari silabus. Rencana Pelaksanaan Pembelajaran ini dibuat untuk memandu guru dalam mengajar agar tidak melenceng keluar dari tujuan pembelajaran (Nainggolan, 2021).

Dengan melihat pentingnya penyusunan perencanaan pembelajaran ini, guru semestinya tidak mengajar tanpa adanya perencanaan. Namun, sayangnya perencanaan pembelajaran yang mestinya dapat diukur oleh kepala sekolah ini, malah tidak dapat diukur. Penyebabnya adalah karena perencanaan pembelajaran, RPP, ada dalam pikiran sang guru. Akibatnya adalah kepala sekolah sebagai pembuat kebijakan di sekolah tidak dapat mengevaluasi kinerja guru secara akademik. Kinerja yang dapat dilihat oleh kepala sekolah hanyalah kehadiran tatap muka, tanpa mengetahui apakah kompetensi guru dalam mengelola pembelajaran sudah sesuai dengan harapan atau belum, atau sudahkah kompetensi dasar yang harus dikuasai oleh siswa terkuasai dengan benar atau tidak (Ahmad Susanto, 2016).

Tabel 1

Daftar Perangkat Pembelajaran yang Dikumpulkan Guru pada Pra-Supervisi

\begin{tabular}{llccc}
\hline \multirow{2}{*}{ No. } & Dokumen & \multicolumn{3}{c}{ Rata-rata } \\
\cline { 3 - 5 } & & $\begin{array}{c}\text { Jumlah } \\
\text { Guru }\end{array}$ & $\begin{array}{c}\text { Jumlah yang } \\
\text { Mengumpulkan }\end{array}$ & Persentase \\
\hline 1. & Program Tahunan & 32 & 32 & $100 \%$ \\
\hline 2. & Program Semester & 32 & 32 & $100 \%$ \\
\hline 3. & Silabus Khusus & 32 & 30 & $93,75 \%$ \\
\hline 4. & $\begin{array}{l}\text { RPP yang disederhanakan (RPP } \\
\text { satu lembar) }\end{array}$ & 32 & 12 & $37,5 \%$ \\
\hline 5. & Program Ulangan/ Evaluasi & 32 & 32 & $100 \%$ \\
\hline \multicolumn{2}{l}{ Nilai Rata-rata Keseluruhan } & 32 & 27,6 & $86,25 \%$ \\
\hline
\end{tabular}

Tabel 2

Daftar Nilai Kualitas RPP yang Dikumpulkan Guru pada Pra-Supervisi

\begin{tabular}{|c|c|c|c|c|}
\hline No & Rentangan & Kategori & Frekuensi & Persentase \\
\hline 1. & $83-100$ & Sangat baik & 6 & $18,75 \%$ \\
\hline 2. & $75-82$ & Baik & 4 & $12,5 \%$ \\
\hline 3. & $66-74$ & Cukup & 2 & $6,25 \%$ \\
\hline 4. & $0-65$ & Kurang & 20 & $62,5 \%$ \\
\hline \multicolumn{3}{|c|}{ Jumlah } & 32 & $100 \%$ \\
\hline
\end{tabular}


Hasil analisis data pada tabel $1 \mathrm{di}$ atas menunjukkan bahwa persentase guru yang mengumpulkan perangkat pembelajaran sangat baik. Hanya saja pada dokumen menyusun RPP yang disederhanakan yang masih sangat kurang yaitu 37,5 persen, atau hanya 12 dari 32 orang guru yang mengumpulkan RPP yang sudah disederhanakan. Dari tabel 2 jelas terlihat bahwa kualitas RPP guru SMA Negeri 1 Bunyu pada tahun pelajaran 2019/2020 termasuk kategori kurang. Dari 32 orang guru yang RPP-nya dianalisis oleh peneliti, hanya rata-rata 6 orang guru yang memiliki RPP kategori sangat baik (18,75\%), kategori baik berjumlah 4 guru (12,5\%), kategori cukup berjumlah 2 guru $(6,25)$, dan kategori kurang berjumlah 20 guru $(62,5 \%)$.

Hasil refleksi terhadap temuan tersebut menunjukkan bahwa faktor yang menyebabkan masih rendahnya kompetensi guru tersebut diduga disebabkan oleh faktor internal dan eksternal. Faktor internal yang diduga mempengaruhi rendahya kompetensi guru menyusun RPP yang disederhanakan antara lain:

1. Guru belum memahami teknik penyusunan RPP yang disederhanakan;

2. Kurangnya motivasi diri untuk meningkatkan kemampuan profesionalnya dalam menyusun rencana pembelajaran khususnya RPP yang disederhanakan.

Faktor eksternal yang diduga mengakibatkan rendahnya kompetensi guru dalam menyusun RPP yang disederhanakan adalah waktu pengumpulan perangkat pembelajaran yang terbatas, satu minggu. Sehingga guru-guru hanya menggunakan perangkat tahun lalu untuk dikumpulkan (Fahrina, Amelia, \& Zahara, 2020). Hasil pengamatan di tahun pelajaran 2019/2020 di SMA Negeri 1 Bunyu didapatkan data sebagai berikut:

1. Hanya $37,5 \%$ guru yang menyusun RPP yang disederhanakan

2. Secara kualitas, RPP yang baik baru mencapai angka 31,25\% yang dibuat oleh guru.

Untuk mengatasi permasalahan tersebut, peneliti yang berkedudukan sebagai kepala sekolah melakukan supervisi akademik berkelanjutan. Dengan metode tersebut diharapkan setelah kegiatan supervisi, guru yang menyusun RPP yang disederhanakan meningkat menjadi 90\%. Oleh karenanya, pada penelitian ini peneliti mencoba untuk mengatasi masalah rendahnya kompetensi guru dalam menyusun RPP yang disederhanakan dengan menerapkan tindakan berupa pendekatan supervisi akademik berkelanjutan yang belum pernah dilakukan sebelumnya. Tindakan tersebut selanjutnya diteliti melalui penelitian tindakan sekolah yang berjudul "Peningkatan Kompetensi Guru dalam Menyusun RPP yang Disederhanakan Melalui Supervisi Akademik Berkelanjutan di SMA Negeri 1 Bunyu" Tahun Pelajaran 2020/2021.

Penelitian terdahulu yang dilakukan oleh (Setyono \& Sudjadi, 2011) menunjukkan bahwa terdapat pengaruh positif kompetensi guru terhadap kinerja guru, dimana apabila kompetensi yang dimiliki oleh seorang guru baik, akan dapat membuat kinerja guru menjadi lebih baik. Hasil penelitian (Pratiwi, 2013) menyatakan terdapat pengaruh positif dari kepemimpinan kepala sekolah menurut persepsi guru terhadap kinerja guru, dimana apabila kepemimpinan seorang kepala sekolah baik menurut persepsi guru maka akan dapat membuat kinerja guru menjadi baik. Selanjutnya dalam penelitian (Setiyati, 2014) menyatakan ada pengaruh yang positif dan signifikan antara 
Peningkatan Kompetensi Guru dalam Menyusun RPP yang Disederhanakan Melalui Supervisi Akademik Berkelanjutan

motivasi kerja terhadap kinerja guru, apabila motivasi kerja seorang guru tinggi maka akan dapat membuat kinerja guru menjadi baik.

\section{Metode Penelitian}

Penelitian ini bertujuan untuk mendeskripsikan pelaksanaan supervisi akademik berkelanjutan guru SMA Negeri 1 Bunyu dalam menyusun RPP yang disederhanakan menggunakan model supervisi klinis. Supervisi model ini merupakan supervisi akademik yang bersifat kolaboratif. Prosedur pelaksanaannya sama dengan supervisi akademik langsung yakni observasi kelas namun dengan pendekatan yang berbeda.

Supervisi klinis adalah pembinaan kinerja guru dalam mengelola proses pembelajaran (Siregar, 2015). Menurut (Artiningsih, 2020) ada dua tujuan supervisi klinis: pengembangan professional dan motivasi kerja guru. Dalam pelaksanaannya menurut (Siregar, 2015) setidaknya ada empat langkah yaitu:

1. Perencanaan pertemuan

2. Observasi

3. Pertemuan berikutnya

4. Refleksi kolaborasi.

Setelah satu siklus selesai diimplementasikan, khususnya sesudah adanya refleksi, kemudian diikuti dengan adanya perencanaan ulang yang dilaksanakan dalam bentuk siklus 2. Teknik pengolahan dan analisis data dilakukan secara kuantitatif dan kualitatif. Teknik pengolahan data secara kuantitatif dilakukan terhadap variabel kompetensi guru yang diperoleh dari hasil pengamatan atau observasi kinerja guru dalam menyusun RPP yang disederhanakan yang terdiri dari tiga komponen yaitu tujuan pembelajaran, kegiatan pembelajaran, dan penilaian atau asesmen

\section{Hasil dan Pembahasan}

\section{Kompetensi Guru dalam menyusun RPP yang disederhanakan siklus 1}

Pada rapat awal tahun pelajaran 2020/2021, peneliti mengimbau dan mengintruksikan kepada seluruh guru untuk membuat perangkat pembelajaran, khususnya RPP yang harus dibuat haruslah memenuhi prinsip efisien, efektif dan berorientasi pada murid sesuai dengan Permendikbud Nomor 14 tahun 2019, yang hanya terdapat 3 komponen inti, tujuan pembelajaran, kegiatan pembelajaran, dan penilaian atau asesmen. Setelah berjalan selama hampir dua bulan, peneliti mengumumkan kepada seluruh guru bahwa pada bulan Oktober 2020 akan dilakukan supervisi terhadap administrasi guru. Pada siklus ini seluruh guru diminta untuk mengumpulkan perangkat pembelajaran tersebut. Selanjutnya peneliti melakukan analisis dan penilaian terhadap kuantitas guru yang menyetorkan perangkat pembelajaran terutama RPP yang disederhanakan. Dari hasil perhitungan peneliti terhadap jumlah guru yang mengumpulkan RPP yang disederhanakan didapatkan data sebagai berikut: 
Tabel 3

Daftar Perangkat Pembelajaran yang Dikumpulkan Guru Siklus 1

\begin{tabular}{|c|c|c|c|c|}
\hline \multirow[b]{2}{*}{ No. } & \multirow[b]{2}{*}{ Dokumen } & \multicolumn{2}{|c|}{ Rata-rata } & \multirow[b]{2}{*}{ Persentase } \\
\hline & & $\begin{array}{c}\text { Jumlah } \\
\text { Guru }\end{array}$ & $\begin{array}{c}\text { Jumlah yang } \\
\text { Mengumpulkan }\end{array}$ & \\
\hline 1. & Program Tahunan & 32 & 32 & $100 \%$ \\
\hline 2. & Program Semester & 32 & 32 & $100 \%$ \\
\hline 3. & Silabus Khusus & 32 & 32 & $100 \%$ \\
\hline 4. & $\begin{array}{l}\text { RPP yang disederhanakan (RPP } \\
\text { satu lembar) }\end{array}$ & 32 & 30 & $93,75 \%$ \\
\hline 5. & Program Ulangan/ Evaluasi & 32 & 32 & $100 \%$ \\
\hline Nilai & Rata-rata Keseluruhan & 32 & 31,6 & $98,75 \%$ \\
\hline
\end{tabular}

Tabel 4

Daftar Nilai Kualitas RPP yang Dikumpulkan Guru Siklus pada 1

\begin{tabular}{|c|c|c|c|c|}
\hline No & Rentangan & Kategori & Frekuensi & Persentase \\
\hline 1. & $83-100$ & Sangat baik & 10 & $31,25 \%$ \\
\hline 2. & $75-82$ & Baik & 6 & $18,75 \%$ \\
\hline 3. & $66-74$ & Cukup & 14 & $43,75 \%$ \\
\hline 4. & $0-65$ & Kurang & 2 & $6,25 \%$ \\
\hline \multicolumn{3}{|c|}{ Jumlah } & 32 & $100 \%$ \\
\hline
\end{tabular}

Dari tabel 3 tentang data jumlah guru yang mengumpulkan perangkat pembelajaran pada siklus 1 terlihat bahwa dengan adanya informasi supervisi akademik terhadap guru ini, dapat meningkatkan kuantitas jumlah guru yang menyusun RPP yang disederhanakan yang sebelumnya hanya $37,5 \%$, mengalami peningkatan kuantitas menjadi 93,75\%. Dari data tersebut juga dapat terlihat ada dua orang guru yang tidak menyerahkan RPP yang disederhankan. Namun persentase guru yang mengumpulkan perangkat pembelajaran berada pada kategori sangat baik, (98,75\%). Dari tabel 4 terlihat bahwa kualitas RPP guru SMA Negeri 1 Bunyu pada tahun pelajaran 2020/2021 termasuk kategori cukup. Dari 32 orang guru yang RPP-nya dianalisis oleh peneliti, hanya 10 orang guru yang memiliki RPP kategori sangat baik (31,25\%), kategori baik berjumlah 6 guru $(18,75 \%)$, kategori cukup berjumlah 14 guru $(43,75)$, dan kategori kurang berjumlah 2 guru $(6,25 \%)$.

Langkah yang peneliti lakukan setelah data pada siklus 1 dianalisis, selanjutnya peneliti melakukan pertemuan dengan seluruh guru di SMA Negeri 1 Bunyu yang berjumlah 32 orang untuk menyampaikan hasil temuan yang sudah diverifikasi. Pada pertemuan itu juga peneliti dan guru-guru melakukan evaluasi, menemukan nilai-nilai apa, mana yang kurang bernilai, dan apa saransaran yang dibutuhkan. Kemudian memutuskan fokus observasi (pendekatan umum, informasi langsung, kolaboratif, atau langsung diri sendiri), mengatur waktu observasi untuk pertemuan berikutnya. Berdasarkan analisis deskriptif terhadap 
Peningkatan Kompetensi Guru dalam Menyusun RPP yang Disederhanakan Melalui Supervisi Akademik Berkelanjutan

kompetensi guru dalam menyusun RPP yang disederhanakan pada siklus 1 ditemukan data guru yang menyusun RPP yang disederhanakan belum melebihi 50\% dan berada pada kategori cukup, sehingga peneliti melanjutkan penelitian ini pada siklus 2.

\section{Kompetensi Guru dalam menyusun RPP yang disederhanakan siklus 2}

Pada siklus 2, peneliti mengarahkan guru yang belum maksimal mengumpulkan perangkat pembelajaran dan RPP yang disederhanakan untuk melakukan tinjauan kembali perangkatnya dengan waktu dua minggu. Peneliti dan tim ahli yang sudah ditunjuk juga memberikan pendampingan kepada guru-guru yang belum maksimal perangkatnya baik secara kelompok ataupun individual untuk bisa menyusun perangkat pembelajarannya dengan memenuhi prinsip efisien, efektif dan berorientasi pada murid sesuai dengan Permendikbud Nomor 14 tahun 2019, yang hanya terdapat 3 komponen inti, tujuan pembelajaran, kegiatan pembelajaran, dan penilaian atau asesmen.

Selanjutnya, peneliti menganalisa/menguji keaslian RPP yang disusun oleh guru. Metode yang digunakan adalah dengan melakukan supervisi kelas. Dari pelaksanaan rencana pembelajaran ini, dapat terlihat keaslian penyusunannya. Hasil dari analisa penguat tersebut, menunjukkan bahwa RPP yang dikumpulkan benar disusun oleh guru yang bersangkutan. Karena terjadi kesesuaian skenario antara perencanaan dan pelaksanaan di kelas. Selanjutnya peneliti melihat ketertiban siswa dalam proses belajar mengajar. Pada tahap ini pula, peneliti mengumpulkan datadata yang terjadi selama tahap pelaksanaan.

Tabel 5

Daftar Perangkat Pembelajaran yang Dikumpulkan Guru pada Siklus 2

\begin{tabular}{llccc}
\hline \multirow{2}{*}{ No. } & \multicolumn{1}{c}{ Dokumen } & \multicolumn{3}{c}{ Rata-rata } \\
\cline { 3 - 5 } & $\begin{array}{c}\text { Jumlah } \\
\text { Guru }\end{array}$ & $\begin{array}{c}\text { Jumlah yang } \\
\text { Mengumpulkan }\end{array}$ & Persentase \\
\hline 1. & Program Tahunan & 32 & 32 & $100 \%$ \\
\hline 2. & Program Semester & 32 & 32 & $100 \%$ \\
\hline 3. & Silabus Khusus & 32 & 32 & $100 \%$ \\
\hline 4. & RPP yang disederhanakan (RPP & 32 & 32 & $100 \%$ \\
\hline 5. & Patu lembar) & 32 & 32 & $100 \%$ \\
\hline & Nrogram Ulangan/ Evaluasi & 32 & 32 & $100 \%$ \\
\hline
\end{tabular}

Tabel 6

Daftar Nilai Kualitas RPP yang Dikumpulkan Guru pada Siklus 2

\begin{tabular}{|c|c|c|c|c|}
\hline No & Rentangan & Kategori & Frekuensi & Persentase \\
\hline 1. & $83-100$ & Sangat baik & 25 & $78,125 \%$ \\
\hline 2. & $75-82$ & Baik & 7 & $21,875 \%$ \\
\hline 3. & 66-74 & Cukup & 0 & $0 \%$ \\
\hline 4. & $0-65$ & Kurang & 0 & $0 \%$ \\
\hline & Jumlah & & 32 & $100 \%$ \\
\hline
\end{tabular}


Dari tabel 5 terlihat adanya perubahan kuantitas jumlah guru yang menyusun RPP yang disederhanakan yang sebelumnya hanya 93,75\%, mengalami peningkatan kuantitas menjadi 100\%. Tabel 6 terlihat bahwa kualitas RPP guru SMA Negeri 1 Bunyu pada tahun pelajaran 2020/2021 termasuk kategori Sangat Baik. Dari 32 orang guru yang RPP-nya dianalisis oleh peneliti, 25 orang guru yang memiliki RPP kategori sangat baik $(78,125 \%)$, kategori baik berjumlah 7 guru $(21,875 \%)$.

Tabel 7

Hasil Penilaian Supervisi Kelas

\begin{tabular}{ccccc}
\hline No & Rentang & Kategori & Frekuensi & Persentase \\
\hline 1 & $83-100$ & Sangat baik & 25 & $78,125 \%$ \\
\hline 2 & $75-82$ & Baik & 7 & $21,875 \%$ \\
\hline 3 & $66-74$ & Cukup & - & - \\
\hline 4 & $0-65$ & Kurang & - & - \\
\hline \multicolumn{7}{r}{ Jumlah } & & 32 & 100 \\
\hline
\end{tabular}

Dari tabel 7 dapat ditarik sebuah kesimpulan bahwa RPP yang dikumpulkan guru adalah bersifat original. Hal ini terlihat dengan cukup besarnya guru mampu melaksanakan pembelajaran sesuai dengan rencana yang dibuat.

3. Kompetensi Guru dalam menyusun RPP yang disederhanakan pada setiap siklus

Dari Hasil Analisis deskriptif terhadap kemampuan guru dalam menyusun RPP yang disederhanakan pada setiap siklus menunjukkan bahwa penerapan supervisi akademik berkelanjutan ini mampu meningkatkan kemampuan guru dalam menyusun RPP yang diserhanakan.

Tabel 8

Peningkatan Perangkat Pembelajaran yang dikumpulkan Guru Setiap Siklus

\begin{tabular}{lccc}
\hline \multicolumn{1}{c}{ Kategori } & Pra-siklus & Siklus I & Siklus II \\
\hline Program Tahunan & $100 \%$ & $100 \%$ & $100 \%$ \\
\hline Program Semester & $100 \%$ & $100 \%$ & $100 \%$ \\
\hline Silabus Khusus & $93,75 \%$ & $100 \%$ & $100 \%$ \\
\hline $\begin{array}{l}\text { RPP yang } \\
\text { disederhanakan (RPP } \\
\text { satu lembar) }\end{array}$ & $37,5 \%$ & $93,75 \%$ & $100 \%$ \\
\hline $\begin{array}{l}\text { Program Ulangan/ } \\
\text { Evaluasi }\end{array}$ & $100 \%$ & $100 \%$ & $100 \%$ \\
\hline
\end{tabular}


Peningkatan Kompetensi Guru dalam Menyusun RPP yang Disederhanakan Melalui Supervisi Akademik Berkelanjutan

Tabel 9

Peningkatan Kualitas RPP yang Dikumpulkan Guru Setiap Siklus

\begin{tabular}{cccc}
\hline Kategori & Pra-siklus & Siklus I & Siklus II \\
\hline Sangat Baik & $18,75 \%$ & $31,25 \%$ & $78,125 \%$ \\
\hline Baik & $12,5 \%$ & $18,75 \%$ & $21,875 \%$ \\
\hline Cukup & $6,25 \%$ & $43,75 \%$ & 0 \\
\hline Kurang & $62,5 \%$ & $6,25 \%$ & 0 \\
\hline
\end{tabular}

Grafik 1. Peningkatan Kualitas RPP yang Dikumpulkan Guru Setiap Siklus

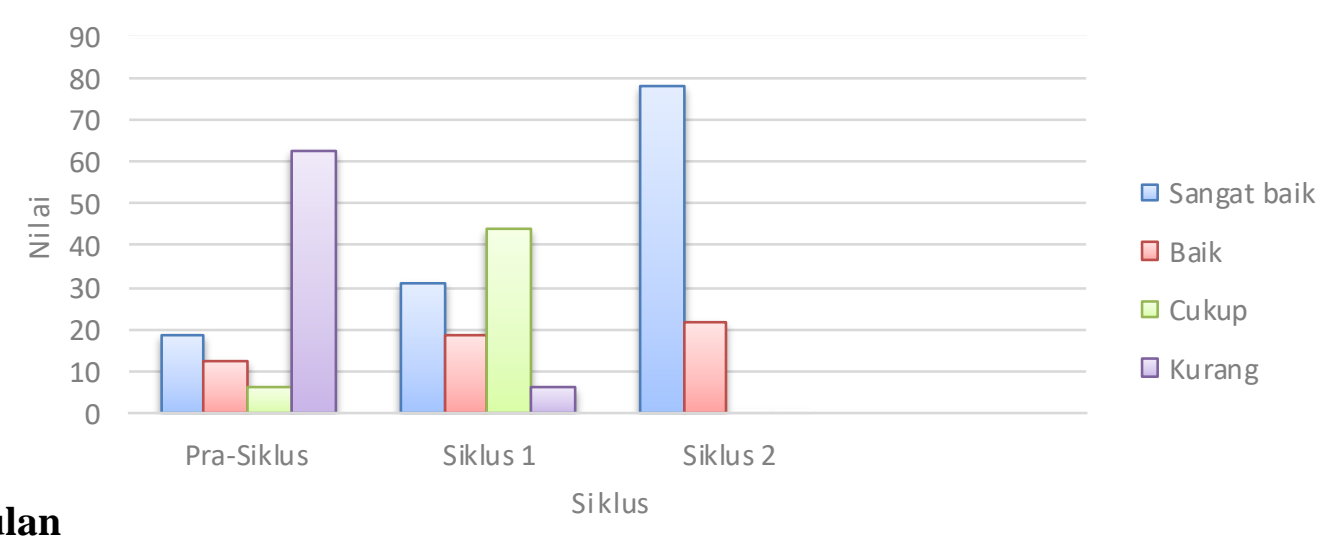

\section{Kesimpulan}

Berdasarkan hasil penelitian yang terurai pada pembahasan mengenai penerapan supervisi akademik berkelanjutan dalam meningkatkan kemampuan guru menyusun RPP yang disederhanakan adalah dapat disimpulkan, Pertama, Supervisi akademik secara berkelanjutan terbukti secara ilmiah dapat meningkatkan kompetensi guru dalam menyusun RPP yang disederhanakan di SMA Negeri 1 Bunyu. Kedua, Langkah-langkah yang mengakibatkan terjadinya peningkatan kompetensi guru menyusun RPP yang disederhanakan. Ketiga, Peningkatan kompetensi guru dalam menyusun RPP yang baik meningkat dan ini bisa terlihat pada tabel 8, tabel 9, dan grafik 1. Adanya perubahan kuantitas jumlah guru yang menyusun RPP yang disederhanakan. Sebelumnya hanya 93,75\%, mengalami peningkatan kuantitas menjadi 100\%. Dari 32 orang guru yang RPP-nya dianalisis oleh peneliti, 25 orang guru yang memiliki RPP kategori sangat baik $(78,125 \%)$, kategori baik berjumlah 7 guru $(21,875 \%)$. 


\section{BIBLIOGRAFI}

Ahmad Susanto, M. Pd. (2016). Teori belajar dan pembelajaran di sekolah dasar. Kencana.Google Scholar

Akhwani. (2020). Integration of TPACK as a Basic Framework for 21st Century Learning: An Analysis of Professional Teacher Competencies. In A. P. Putra, N. L. S. Nuraini, P. S. Cholifah, E. Surahman, D. A. Dewantoro, T. A. Rini, R. F. Pradipta, K. M. Rahar. Atlantis Press. Google Scholar

Artiningsih, Tri. (2020). Peningkatan Kompetensi Profesionalisme Dalam Proses Pembelajaran Melalui Supervisi Klinis Bagi Guru. Didaktikum, 20(1). Google Scholar

Fahrina, Afrillia, Amelia, Karla, \& Zahara, Cut Rita. (2020). Minda Guru Indonesia: Pandemi Corona, Disrupsi Pendidikan, dan Kreativitas Guru (Vol. 153). Syiah Kuala University Press. Google Scholar

Gelen, Ismail. (2018). Academicians'predictions Of 21st Century Education And Education In The 21st Century. European Journal of Education Studies. Google Scholar

Hariyanto, Muchlas Samani. (2013). Konsep dan Model Pendidikan Karakter. Bandung: PT. Remaja Rosdakarya. Google Scholar

Harun, Cut Zahri. (2013). Manajemen pendidikan karakter. Jurnal Pendidikan Karakter, (3). Google Scholar

Hidayat, Asep Saepul. (2012). Manajemen sekolah berbasis karakter. Asian Journal of Innovation and Entrepreneurship, 1(01), 8-22. Google Scholar

Nainggolan, Jusman. (2021). Peningkatan Kemampuan Guru Dalam Pengembangan Silabus Dan Rpp Melalui Pola Pembinaan Profesional Dengan Pendekataan Kooperatif Di Sman 9 Kec. Medan Labuhan Semester 2 Tahun Pelajaran 2017/2018. PROVIDENSI: Jurnal Pendidikan Dan Teologi, 4(1), 122-142. Google Scholar

Pratiwi, Suryani Dewi. (2013). Pengaruh motivasi kerja, kepuasan kerja, kepemimpinan kepala sekolah menurut persepsi guru, dan iklim sekolah terhadap kinerja guru ekonomi SMP Negeri di Kabupaten Wonogiri. S2 Pendidikan Ekonomi, 2(1). Google Scholar

Rini, Amanda Pasca, \& Muhid, Abdul. (2021). Model Pembelajaran Guided Discovery Learning, Apakah Efektif dalam Meningkatkan Kemampuan Berfikir Kritis Siswa? Edukatif: Jurnal Ilmu Pendidikan, 3(5), 2311-2320. Google Scholar

Setiyati, Sri. (2014). Pengaruh kepemimpinan kepala sekolah, motivasi Kerja, dan budaya sekolah terhadap kinerja guru. Jurnal Pendidikan Teknologi Dan Kejuruan, 22(2), 200-206. 
Peningkatan Kompetensi Guru dalam Menyusun RPP yang Disederhanakan Melalui

Supervisi Akademik Berkelanjutan

Setyono, Hendro, \& Sudjadi, Achmad. (2011). Pengaruh Kompetensi Guru, Insentif Dan Lingkungan Kerja Fisik Terhadap Kinerja Guru Sma Negeri 1 Patimuan Kabupaten Cilacap. Sainteks, 8(2). Google Scholar

Siregar, Deni. (2015). Kontribusi Kinerja Guru Dalam Mengelola Proses Pembelajaran Dan Motivasi Belajar Siswa Terhadap Hasil Belajar Ips Siswa Kelas VII MTs Mu'allimin Nw Pancor (Studi Persepsi Para Siswa Kelas VII MTs Mu'allimin NW Pancor). Educatio, 10(2), 233-248. Google Scholar

Sugiarta, I. Made, Mardana, Ida Bagus Putu, \& Adiarta, Agus. (2019). Filsafat Pendidikan Ki Hajar Dewantara (Tokoh Timur). Jurnal Filsafat Indonesia, 2(3), 124-136. Google Scholar

Copyright holder :

Jasmin (2021)

First publication right :

Syntax Idea

This article is licensed under:

(c) (i) (O) 